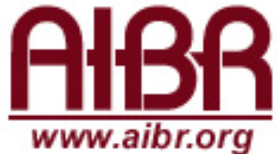

REVISTA DE ANTROPOLOGÍA IBEROAMERICANA

ESTIMADO LECTORIA:

GRACIAS POR DESCARGAR ESTE ARTÍCULO. EL TEXTO QUE ESTÁ A PUNTO DE CONSULTAR ES DE ACCESO LIBRE Y GRATUITO GRACIAS AL TRABAJO Y LA COLABORACIÓN DESINTERESADA DE UN AMPLIO COLECTIVO DE PROFESIONALES.

USTED PUEDE AYUDARNOS A INCREMENTAR LA CALIDAD Y A MANTENER LA LIBRE DIFUSIÓN DE LOS CONTENIDOS DE ESTA REVISTA A TRAVÉS DE SU AFILIACIÓN A LA ASOCIACIÓN AIBR:

http://www.aibr.org/antropologia/aibr/socios.php

La afiliación a AIBR tiene un coste mínimo al año, y le proporcionará las siguientes ventajas y privilegios:

1. Recibir en su domicilio la revista impresa, en Europa y América (tres números anuales), así como todas las novedades relativas al funcionamiento de la asociación

2. Recibir en su domicilio, a precio especial o de forma gratuita, cuantas publicaciones adicionales edite la asociación.

3. Derecho a voto en las asambleas de socios, así como a presentarse como candidato a la elección de su Junta Directiva.

4. Recibir el boletín de socios (tres números anuales), así como la información económica relativa a cuentas anuales de la asociación.

5. Beneficiarse de las reducciones de precio en congresos, cursos, libros y todos aquellos convenios a los que a nivel corporativo AIBR llegue con otras entidades. En este momento, existen los siguientes acuerdos:

o Reducción de un $20 \%$ en el precio de todos los libros publicados por la editorial MELUSINA.

o Reducción de un $20 \%$ en el precio de todos los libros publicados por la editorial SEPHA.

o Reducción de un 30\% en el precio de todos los libros publicados por la editorial GRAN VÍA.

o Derecho a cuota reducida en los congresos trianuales de la FAAEE (España) y a los bianuales de la Sociedad Española de Antropología Aplicada.

o Derecho a cuota reducida en los congresos la IUAES.

6. Promoción gratuita, tanto a través de la revista electrónica como de la revista impresa, de aquellas publicaciones de las que sea autor y que estén registradas con ISBN. La difusión se realiza entre más de 5.200 antropólogos suscritos a la revista.

7. Cuenta de correo electrónico ilimitada de la forma socio@aibr.org, para consultar a través de webmail o cualquier programa externo.

8. Espacio para web personal de la forma http://www.aibr.org/(directorio)/(nombre) y cuenta propia de ftp.

9. Acceso con clave a todos los documentos de la Intranet de socios de AIBR, incluida la consulta a artículos en proceso de evaluación de la revista AIBR.

10. Promoción gratuita a través de la revista (banner rotativo y reseña) de aquellos eventos, congresos, conferencias o cursos en los que usted forme parte del comité organizador.

11. Opción a formar parte como evaluador de los artículos recibidos por la revista.

IMPORTE DE LA CUOTA ANUAL: Hasta diciembre de 2008, la cuota única anual es de 32 (euros). Su validez es de un año a partir del pago de la cuota. Por favor, revise la actualización de cuotas en nuestra web.

PARA HACERSE SOCIO DE AIBR, POR FAVOR, CONSULTE LA SIGUIENTE DIRECCIÓN:

http://www.aibr.org/antropologia/aibr/socios.php 


\title{
A 3 EN TORNO AL USO DE ENSALMOS TERAPÉUTICOS EN EL NOROESTE ARGENTINO Y SUS FUNDAMENTOS MITICO- RELIGIOSOS
}

\section{Anatilde Idoyaga Molina ${ }^{1}$ y Francisco Sacristán Romero ${ }^{2}$}

\author{
${ }^{1}$ Consejo Nacional de Investigaciones Científicas y Técnicas. \\ ${ }^{2}$ Universidad Complutense de Madrid.
}

Recibido: 27 de septiembre de 2007 Aceptado: 4 de febrero de 2008

\begin{abstract}
Resumen
Los autores analizan las prácticas terapéutico-rituales en las medicinas tradicionales del Noroeste Argentino, enfocando los ensalmos sus fundamentos y significados. En primer lugar, a fin de contextualizar el uso de ensalmos, se refieren diferentes concepciones y rituales que dejan ver la influencia de la tradición católica en las prácticas de legos y de curanderos, a la vez que mencionan la importancia que tiene en tales la reformulación de las tradiciones de la medicina humoral o académica en el área de estudio. En segundo término, se concentran en el ritual terapéutico de la cura de palabra o ensalmo, haciendo notar que esas fórmulas poseen un fundamento mítico- religioso, que resulta de la mitificación de la vida de Cristo a través de los evangelios, de la mitificación de las vidas de algunos santos y de los múltiples mitos remanecidos sobre la Virgen. El ensalmo es, entonces, el rito que actualiza el mito, vale decir, el tiempo originario y, con ello, el carácter sagrado de los seres que intervienen y de las acciones que se narran. Esta postura los lleva a polemizar con otros autores que han incluido a los ensalmos entre los tratamientos de la salud de carácter mágico admitiendo la existencia de una terapéutica católico-religiosa
\end{abstract}

\author{
Palabras Clave \\ Ensalmos, Enfermedad, Terapia, Noroeste Argentino
}

ON THE USE OF THERAPEUTICAL SPELLS IN THE NORTHWEST OF ARGENTINA AND ITS MYTHIC AND RELIGIOUS BASIS

\begin{abstract}
The authors study the ritual-therapeutic practices of formulas, or spells, in traditional medicines among the Creole from North-Western Argentina. Firstly, after contextualizing the use of spells, the authors describe different conceptualizations and rituals found in both lay and specialists' (curanderos) practices that have been influenced by Catholic traditions. They also discuss the significance of reformulated praxis in humoral medicine in the area. Secondly, they concentrate on the actual words or spell of the cure in the therapeutic ritual, noting that these formulas posess a mythic-religious foundation which results in the mythification of the life of Christ through the gospel, in the mythification of the lives of various saints, and in the
\end{abstract}


multiple myths regarding the Virgin Mary. The spell is, then, the rite that actualizes the myth and inserts the past in the present. The spell realizes the sacred power of both the beings that intervene and the actions that they narrate. With this interpretation, the authors argue for the existence of Catholic religious therapies despite the fact that other scholars have located spells within magical therapeutic practices.

\section{Key Words}

Formulas, Illness, Therapy, North Western Argentina

\section{Introducción}

A fin de explicar las crecientes estrategias de complementariedad terapéutica desarrolladas por los usuarios Kleinman (1980: 50) propuso enfocar la atención de la salud como un sistema cultural local compuesto por el solapamiento de tres medicinas: "...popular, professional, and folk sectors". Recuperando esta visión, nos pareció que la traducción literal de los términos se prestaba a confusión español, especialmente el término popular que no es habitualmente entendido en español como auto-atención, autotramiento, o medicina doméstica, vale decir la práctica de los legos no sólo frente a los profesionales de la biomedicina, sino particularmente frente a los especialistas y/ o profesionales de otras medicinas, tales como curanderos, acupunturistas, reflexólogos, entre muchos otros $^{1}$. Las tres categorías propuestas nos parecieron escasas para dar cuenta de la complejidad de la oferta y de la posibilidad de articular las estrategias de complementariedad con factores culturales socioeconómicos, étnicos y regionales entre otros aspectos. En este sentido preferimos hablar de una configuración etnomédica que explica la atención como traslapos entre las siguientes medicinas: a) biomedicina -incluyendo las psicoterapias- b) medicinas tradicionales -que en la Argentina son el curanderismo y los shamanismos- c) el autotratamiento -la práctica de legos en el contexto familiar y comunitario- $d$ ) las medicinas alternativas -aquellas difundidas especialmente en las últimas décadas, en muchos casos en relación de los fenómenos de new age- como el yoga la acupuntura, el shiatsu, la aromaterapia,

\footnotetext{
${ }^{1}$ Cuando hablamos de medicinas alternativas no lo hacemos en el sentido biomédico, como opuestas a las complementarias (las legitimadas por la biomedicina), en virtud de que siempre privilegiamos las concepciones y los comportamientos de los actores sociales a quienes en el momento de optar por una medicina "no convencional" no muestran interés alguno en la opinión de los biomédicos. Lo que es más la combinación de medicinas es normalmente ocultada a los profesionales (Csordas y Kleinman, 1996, Idoyaga Molina y Luxardo, 2005).
} 
la terapia de vidas pasadas, entre muchas otras de un número siempre creciente de nuevas especialidades, e) las terapias religiosas definidas como las ofertas de sanación y tratamiento de la aflicción que se dan con los contextos de las Iglesias de lo que Weber llamó religiones institucionalizadas. En Argentina -como en la mayoría de las sociedades- se trata de las terapias rituales y de otras variantes que se ofrecen en la Iglesia Católica y en las Iglesias Pentecostales, que son abiertas al público en general, a diferencia de los servicios que se pueden encontrar en el contexto del judaísmo y entre los musulmanes.

Se nos podrá objetar que algunas de las medicinas definidas como alternativas son, por ejemplo, tradicionales en las sociedades orientales, tal como es el caso del yoga o la acupuntura. No obstante, no son tradicionales en la Argentina, no están dirigidas a captar el mismo tipo de usuario, son de carácter citadino y usualmente de costos en más o menos relevantes. Por lo tanto, aunque aparezcan en la oferta no acceden a ellas los individuos de todos los sectores socioeconómicos poniendo de este modo un límite a las estrategias de complementariedad terapéutica que recurriría cualquier enfermo, si contara con las posibilidades libertad para hacerlo.

En cuanto a las terapias religiosas, deseamos resaltar que cuentan con especialistas: aquellos que poseen el don o el carisma para sanar, hecho que es importante porque a los actores sociales no les resulta relevante si su capacidad deviene de una experiencia más parecida a una iniciación shamánica que a un aprendizaje formalizado.

Por otra parte, como hemos señalado anteriormente (Idoyaga Molina, 2005) cada medicina genera sus propias formas de auto-atención, así existe una autoatención de raigambre biomédica, otras generadas en las terapias alternativas -v. g. la ejecución de prácticas de yoga, control mental o la terapia que fuere, realizadas individual o grupalmente, que inicialmente fueron aprendidas e integradas a través de la consulta a los especialistas- y religiosas -e. j. los grupos de oración-, finalmente, existe un autotratamiento o praxis de auto-atención vinculadas al curanderismo. Se trata de saberes y prácticas a la que denominamos autotratamiento tradicional o medicina doméstica.

El Noroeste Argentino (NOA) fue conquistado por los Incas y unos 50 años más tarde por los españoles, iniciándose un proceso de colonización que implicó la 
deculturación de las sociedades nativas y la imposición de saberes, costumbres y valores de la sociedad dominante. Si bien no puede hablarse de genocidio, más allá de la merma población implicada por la conquista sí se puede hablar de etnocidio en el sentido de la aniquilación de la cultura de una sociedad.

El aporte de población foránea fue principalmente de españoles, italianos y árabes. Obviamente, los españoles llegaron en sucesivas y continuas oleadas migratorias, los italianos arribaron especialmente a fines del siglo XIX y principios de $\mathrm{XX}$, mientras que los árabes también se sumaron a través de distintas corrientes desde el siglo XVII al XX.

La medicina tradicional del NOA es el curanderismo, al igual que en el resto del país incluso en zonas donde los inmigrantes se instalaron tras la aniquilación de las sociedades indígenas, como sucedió en buena parte de la región pampa santafecina o en la provincia de La Pampa. La forma de auto- atención relacionada con el curanderismo es la que hemos denominado medicina doméstica o autotramiento tradicional. Entre los inmigrantes llegaron curanderos y legos capaces de poner ventosas, recomendar un té de tal o cual vegetal según los malestares del enfermo. Éstos se instalaron tanto en áreas rurales como en las ciudades -incluida Buenos Aires.

En virtud de nuestra larga experiencia de campo, no sólo en el NOA sino en las más diversas regiones del país -a excepción de la Patagonia- entre europeo lamericanos, árabe/ americanos, bereberes/ americanos y mestizos, estamos en condiciones de afirmar que las nociones y prácticas relativas a la concepción y tratamiento de la enfermedad por parte de curanderos y de legos son básicamente similares en todo el país ${ }^{2}$.

Tanto el curanderismo como la medicina doméstica o autotratamiento tradicional básicamente sintetizan: a) antiguas tradiciones biomédicas, muchas de raigambre humoral ${ }^{3}$, b) saberes y prácticas sobre la enfermedades y el tratamiento de otros infortunios, el reconocimiento del curanderismo y de la existencia de legos

\footnotetext{
${ }^{2}$ Idoyaga Molina ha realizado trabajo de campo además entre indígenas del Gran Chaco como los Pilagá, Toba, Mataco o Wichí, Chulupí, Chiriguano y Ayoreo

3 Incorporamos la medicina humoral en la "biomedicina", porque la medicina actual reconoce sus raíces y su desarrollo histórico a partir del nacimiento en la medicina humoral en Grecia. A la vez, si bien muchas tradiciones humorales fueron dejadas de lado, otras siguieron en vigencia hasta el Siglo XIX, tales como la aceptación de la taxonomía de individuos y grupos sociales según temperamentos, la diferenciación entre enfermedades nerviosas y mentales hasta el XX y otras técnicas tienen aún vigencia, como "tomar el pulso".
} 
capaces de ejercer algunas terapias de raigambre popular aportados por los inmigrantes y, c) rituales terapéuticos en su mayoría de origen católico que fueron en muchos casos inicialmente prácticas de elite, luego abandonadas y que se mantuvieron vigentes entre los sectores llamados populares, tal es el caso de los ensalmos (Idoyaga Molina, 1999/2000). Es en ese marco cosmovisional en el que posiblemente en el NOA se incorporaron algunos elementos de origen indígena. Esta opinión puede no ser compartida por otros especialistas que han hecho trabajo de campo en el NOA, sin embargo quisiéramos hacer notar que antes de considerar el origen indígena a tal o cual enfermedad o forma terapéutica, es necesario no sólo conocer el folklore español (en nuestro caso deberíamos decir las prácticas del curanderismo aún vigentes en España) como sugería Redfield (1934:59), sino también la antigua medicina de elite como afirma Foster (1994: 153-58) y las concepciones religiosas bajo medievales y modernas, como hacemos notar nosotros ${ }^{4}$.

Asimismo, queremos llamar la atención sobre la necesidad de distinguir saberes y prácticas de los especialistas o curanderos de los saberes y prácticas de los legos, en virtud de que se suele confundir la medicina doméstica con el curanderismo y al lego con el especialista. Por otra parte, en la bibliografía tradicional se ha prestado poca atención a la influencia católica, que dejan ver muchos de los rituales terapéuticos y otras actividades relacionadas con la enfermedad y la salud, tal como sucede con los ensalmos (Palma, 1978; Pérez de Nucci, 1989).

En esta oportunidad enfocamos la práctica y la significación del ritual terapéutico denominado ensalmo, conocido también en la Argentina como "cura de palabra" y "cura por secreto" en el marco de las praxis curativas del NOA. A fin de contextualizar el tema de análisis, inicialmente nos referiremos rápidamente a algunos rituales terapéuticos ejecutados por legos y curanderos, que dejan ver la manipulación de símbolos y de entidades sagradas del catolicismo. Al concentrarnos en los ensalmos, mostraremos su fundamento en la tradición mítica Judeocristiana

\footnotetext{
${ }^{4}$ Inicialmente en relación con el NOA descontábamos que encontraríamos unas síntesis cultural entre tradiciones indígenas y españolas. Sin embargo, la profundización de nuestro trabajo de campo durante 10 años, más la lectura sistemática de trabajos etnográficos sobre la medicina tradicional actual en España e Italia, así como de los saberes y técnicas de la medicina occidental oficial y de las concepciones religiosas desde la baja edad media en adelante, nos llevaron a asumir la posición que hoy sostenemos.
} 
con el soporte etnográfico pertinente, posteriormente discutiremos la pertinencia de las categorías teóricas utilizadas por otros autores.

En la perspectiva planteada es central el concepto teórico de mito, al que entendemos, en el contexto de las corrientes hermenéuticas y fenomenológicas, como un relato verdadero, explicito o implícito $^{5}$, actualizable, fundante y metatemporal ${ }^{6}$, frecuentemente arquetípico, sagrado y etiológico, es a la vez un hecho vivido y experimentado antes que intelegido (Cassirer, 1969, Eliade, 1968 y 1972; Gusdorf, 1960; Leenhardt, 1961). A la vez en lo que hace a la relación entre mito e historia acordamos con las nuevas posturas teóricas, expuestas en las últimas décadas que hacen hincapié en la comprobable incorporación de hechos históricos en el mito, a fin de re-elaborar la situación de contacto interétnico con los blancos, expresando los cambios en términos de las estructuras de pensamiento de las sociedades nativas. La profundización del estudio del fenómeno en cuestión, permitió redefinir al mito como conciencia histórica, social y política, a la vez que entender la relación entre mito e historia como un nexo de ida y vuelta que, hace posible hablar de historificación del mito y mitificación de la historia (Guss, 1981;Hill, 1988; Sahlins, 1981; Turner 1988 a y b).

En este contexto, la historia de la vida Cristo es un claro ejemplo de mitificación de la historia e historificación del mito, más allá que el registro constituido por los Evangelios no se mantenga por vía oral (Idoyaga Molina, 2001). Es claro que la vida de Cristo narrada por los evangelistas intencionalmente se entronca -a través de la temática del Mesías- con el mito cosmológico y fundante de los hebreos, conocido en las tradiciones cristianas -incluido el catolicismo- como Antiguo Testamento. Este proceso de mitificación de la vida de Cristo le confiere la

\footnotetext{
${ }^{5}$ Cuando hablamos de relato implícito nos referimos a cantos, fórmulas y otros tipos discursivos que se utilizan con fines preventivos, terapéuticos, propiciatorios, entre otros objetivos. Estas expresiones remiten y adquieren sentido en una narración que no ha sido explicitada porque no lo exige la situación en que las expresiones son utilizadas, tal como sucede entre grupos indígenas de Sur América, como los Ayoreo o los Huachipaire. Ahora bien, dado el tema de este artículo, daremos un ejemplo tomado de las prácticas del catolicismo, así cuando una persona jura por Dios lo que fuere, se está remitiendo al episodio mítico en el que el Dios cristiano entregó las Tablas de la Ley a Moisés explicitando los Mandamientos, hecho que hoy garantiza la verdad de lo enunciado por quien jura, dado que en caso contrario estaría violando el segundo mandamiento.

${ }^{6}$ Se dice que el mito es metatemporal para indicar que esta por fuera, más allá, del tiempo cronológico. En este sentido, si bien ocurrió en el tiempo primigenio es actualizable llega hasta el presente a través del ritual, de la enunciación de una formulas entre otros procedimientos. Así por ejemplo en el ritual cada la misa se actualiza, se vuelve presente la muerte y resurrección de Cristo. Es en este sentido, que Gusdorf (1969) señala que el mito facilita que el hombre sea contemporáneo a la cosmogonía.
} 
condición de realidad trascendente, como sucede con los hechos históricos que se incorporan en los corpus mitológicos.

Los materiales sobre los que nos basamos fueron recabados en numerosos trabajos de campo, iniciados en 1997. Los datos fueron obtenidos a través de entrevistas abiertas, extensas y recurrentes a informantes calificados y grupos naturales (Coreil, 1995). Realizamos además, observación y observación participante. El material fue recogido con magnetófono y posteriormente trascrito. Los relatos aquí presentados son parte de esa casuística.

Esta contribución es parte de los resultados alcanzados a través de sucesivos proyectos de investigación, financiados y auspiciados por el Consejo Nacional de Investigaciones Científicas y Técnicas (CONICET), la Secretaría de Ciencia, Tecnología e Innovación Productiva y el Instituto Universitario Nacional del Arte de la Argentina y el Grupo Hispano Latinoamericano de Investigación en Comunicación de la Universidad Complutense de Madrid, instituciones a las que agradecemos expresamente.

\section{Las medicinas tradicionales y los rituales terapéuticos}

Son medicinas tradicionales en el NOA el curanderismo y el autotratamiento tradicional o medicina casera. El autotratamiento es la terapia ejercida por los legos, en cambio el curandero es el especialista de la medicina tradicional, capaz de atender cualquier tipo de mal. Usualmente son clarividentes y pueden propiciar el desarrollo de los cultivos, del ganado, y colaborar en la solución de problemas económicos y afectivos que, junto con la salud, son los más importantes motivos de consulta. Más allá de esta faz benigna, el curandero es un ser ambivalente capaz de hacer daños, que van desde la enfermedad y la muerte hasta cualquier tipo de pérdidas (Idoyaga Molina, 2000 a y b, 2002 a; Palma, 1978; Pérez de Nucci, 1989).

Nos concentraremos en algún ritual terapéutico de raigambre católica aludiendo al contexto en que se presenta. La medicina casera incluye la preparación de remedios y los ensalmos. La mayoría de las recetas son de origen vegetal y tienen fundamento en la clasificación de las enfermedades, las terapias y los alimentos en cálidos y fríos (Idoyaga Molina, 1999), lo que devela su raigambre 
humoral. La cura de palabra designa a fórmulas en las que se invoca y se actualiza el poder de las deidades. A menudo van acompañadas de acciones rituales y símbolos del catolicismo, como la señal de la cruz, el rezo y la utilización de agua bendita y aceite (Idoyaga Molina, 2001: 15-17). Esta práctica llevada a cabo por legos no debe confundirse con las sanaciones realizadas hoy en día en los cultos católicos -incluidos los carismáticos- y evangélicos, que son emergentes contemporáneos con sustento en la noción de carisma o don. Es decir, entre los clérigos y fieles hay individuos con carismas especiales, entre los que figura el de curar.

Los curanderos son especialistas terapéuticos, sus técnicas incluyen el conocimiento y prácticas fundadas en antiguas teorías biomédicas, así como un conjunto de procedimientos rituales en su mayoría de origen católico, que muestran el manejo de poder por parte del especialista (Idoyaga Molina, 2001). Las prácticas tradicionales de legos y de especialistas manipulan lo sagrado católico, que es parte de la herencia hispánica.

En relación con la médica académica, cabe aclarar que los conceptos de la medicina humoral fueron refigurados. La transfiguración más significativa consiste en que dejó de ser una explicación natural de los procesos de enfermedad y terapia para incluir contenidos mítico-religiosos y nociones de poder. Así, se clasificaron dolencias como la brujería ${ }^{7}$, en términos humorales de frío y cálido (Idoyaga Molina, 1999: 16-17). La cura dejó de responder a un modelo natural en virtud de que los vegetales o los elementos involucrados son percibidos como portadores del poder que anima a los entes naturales. Esta flexibilización fue un proceso generalizado en América Latina, de acuerdo a Moll (1944: 130) los rezos fueron categorizados en fríos (el salve) y cálidos (el credo). En México incluso los terapeutas se clasificaron en cálidos y fríos (Álvarez Heydenreich, 1992: 128).

En el NOA, desde la perspectiva de los actores, la sanación se debe al consumo de remedios y a las acciones simbólicas que se realizan, tales como la

\footnotetext{
${ }^{7}$ Con la expresión brujería, en el NOA como en otras partes de América Latina, la población refiere tres fenómenos diferentes: a) en primer lugar es la denominación de una enfermedad ocasionada por intencionalmente por otras personas, se usan como sinónimos, mal postizo, mal puesto, daño y mal hecho, b) en segundo término brujería indica la ejecución de acciones dañinas como se advierte en la frase "le hicieron brujería y, c) en tercera instancia refiere el fenómeno de la brujería de raigambre europea, entendida como una forma de daño específica, distinta de la hechicería, siguiendo la ya clásica distinción propuesta por Murdcok entre witchcraft (brujería) y sorcery (hechicería) (1980: 6471).
} 
señal de la cruz o las oraciones que suelen acompañar la preparación y/o el consumo de los fármacos. Por ejemplo, se acostumbra rociar los elementos que se adosan a la cataplasma haciendo una cruz. En definitiva, los símbolos del catolicismo refuerzan el proceso de cura, pues se apropian del poder ritual de las acciones ejecutadas.

Algunas prácticas rituales comparten legos y curanderos, tal es el caso del método diagnóstico-terapéutico para el mal de ojo, la medida para el empacho, el tratamiento con tinta china para la culebrilla, el recorte del pie sobre la hoja de una higuera o de la tuna para las hemorroides, entre otros procedimientos que suelen combinarse con los ensalmos.

El mal de ojo se presenta en síntomas polimorfos como cefaleas, inapetencia, desgano, desasosiego y otros. La explicación etiológica admite dos posibilidades: a) un origen natural producido por contagio a través del aire y b) una teoría que involucra el poder y, a veces, la intención de una persona. En este último caso, hay dos posibilidades, por un lado provocan la enfermedad los celos, los malos deseos y sentimientos de las personas que miran, tocan o piensan en niños o seres más débiles, lo que equivale a decir que el mal resulta de la acción intencional de un ser humano. Por otro, causan involuntariamente mal de ojo las personas de gran energía o fuerza que añoran, piensan, miran o tocan a otra, produciéndole un desbalance energético (Idoyaga Molina, 2002 a y 2006). Estas últimas ideas se alejan de la medicina oficial del siglo XVI, haciendo intervenir sentimientos, intenciones, fuerzas y poderes. Son un buen ejemplo de los saberes y prácticas populares (o no) traídas por los inmigrantes, en especial españoles, italianos y árabes. Lo que queremos decir es que nociones y acciones que, si bien podían ser rechazadas por la medicina académica (o no, según el especialista), eran compartidas por individuos de diferentes sectores sociales y no exclusivos de los grupos populares.

En la Puna, como notó Palma, las teorías etiológicas sobre mal de ojo aludían a causas naturales, a diferencia de lo que sucedía en el resto del NOA (1978: 155156). Lo mismo comprobamos en nuestro trabajo de campo tiempo después, aunque 
algunas de las curanderas puneñas ya habían oído de otras explicaciones y hasta nos solicitaron que las ilustráramos al respecto ${ }^{8}$.

Para tratar el mal de ojo la técnica diagnóstico-terapéutica más común es la del agua y el aceite, a la que se suma la terapia por ensalmos. Se dice que si las gotas de aceite derramadas en el agua se expanden en pequeños círculos, la dolencia es el mal de ojo, pues los círculos representan la mirada que causó el mal. A la vez, la técnica descrita inicia la cura, que tras repetirse tres veces, permite la recuperación de la salud por medio del ritual.

El poder del aceite y del agua -recordemos que ambos se usaron y se usan en los rituales del bautismo- se asocia a las representaciones del cristianismo de claro contenido purificatorio y expiatorio. Dichos elementos eliminan las energías negativas del cuerpo del doliente, así como eliminan el pecado en la ceremonia del bautismo.

Entre las técnicas que el curandero maneja algunas tienen relación con dolencias específicas -por ejemplo el llamado del alma del sufriente de susto- otras son apropiadas para cualquier mal -por ejemplo el sahumado- y algunas son específicas de un sanador en particular -por ejemplo, una de nuestras informantes (curandera)- entre sus prácticas impone la imagen del santo, que es su principal auxiliar, sobre el cuerpo del paciente.

En la praxis terapéutica, la acción ritual y el concomitante manejo del poder es continuo, la cura involucra a deidades, las fuerzas de algunos ámbitos, otros seres humanos poderosos y la calificación del espacio y del tiempo. El terapeuta se enfrenta a brujos causantes de daños, a ambientes terribles que provocan

\footnotetext{
${ }^{8}$ En relación con la sistematización de las teorías etiológicas de la enfermedad, las ya clásicas propuestas de Foster (1976), Young (1976) y Murdock (1980), entre otras formulaciones, nos resultaron inadecuadas por diversos motivos que discutimos en otra oportunidad (Idoyaga Molina, 2005 b). Concretamente en relación con el NOA propusimos hablar de: 1) desequilibrios orgánicos, que se explican por causas denominadas habitualmente naturales, como los problemas digestivos causados, por el empacho, la insolación por la exposición excesiva a los rayos del sol, golpes, etc. 2) Desequilibrios entre las entidades de la persona para referir los males que se originan en la pérdida de las entidades anímicas.3) Desequilibrios sociales incluyendo aquellos males que se engendran en la interacción social o que necesitan la vida social, tales como el mal de ojo, la envidia y la brujería o daño, también conocido como mal hecho y mal postizo.4) Desequilibrios espacio- ambientales en esta categoría incluimos las enfermedades que trasmite el ambiente corrompido, un caso típico es el mal aire. 5) Desequilibrios religioso-rituales, concepto que engloba las enfermedades causadas por los seres míticos, ya fuere por incumplimiento ritual o mezquindad en las ofendas, transgresión de tabúes o la mera malignidad de la entidad, tal como sucede con el Diablo (Ver Idoyaga Molina, 2000 y 2002). Esta clasificación sufrió variantes a partir de las críticas que no hicimos, al plantear esta vez una nueva sistematización de carácter universal (Idoyaga Molina, 2005 b). La que por cuestiones de espacio nos resulta inoportuno reseñar.
} 
enfermedades y a deidades, algunas decididamente negativas como el Diablo y otras que, aunque más benignas, provocan dolencias y otros perjuicios como represalia a las ofensas y faltas que se cometen.

Entre las prácticas y nociones rituales que remiten al catolicismo figuran la repetición de la señal de la cruz, la invocación y los rezos a las deidades, tales como Dios Padre, el niño Dios de Praga, la Virgen en sus múltiples manifestaciones y los santos, que son los seres míticos con que los curanderos cuentan más frecuentemente entre sus auxiliares. A ellos suelen sumarse las almas de muertos recientes que o bien son parientes del especialista o entidades anímicas de poderosos y respetados curanderos ${ }^{9}$.

Por su parte, la triple repetición que exige la mayoría de las acciones terapéuticas, tiene su fundamento en la Trinidad, cada una de las veces se hace el ritual en nombre de una de las Tres Personas: Dios Padre, Cristo y el Espíritu Santo. Esta repetición nos remite a la Trinidad, que es un poderoso símbolo de fe y del misterio de lo sagrado, en el sentido de lo numinoso analizado por Otto (1965). La triple repetición es parte misma del ritual y, si bien el poder del tres deviene de la Trinidad, esta asociación transformó al tres en número sagrado, al parecer independizándolo como vehículo de poder de la entidad cristiana.

De igual modo se asocian a las concepciones del catolicismo los lavados purificatorios, la ingestión de agua bendita y el sahumado de pacientes y de espacios. Recordemos que anteriormente el sahumado era una práctica corriente en el ritual de la misa, cuyo significado era justamente el de proporcionar sanación física y espiritual a los fieles participantes del rito. Al respecto, vale la pena destacar que se trata de un procedimiento todavía vigente en las ceremonias de las Iglesias ortodoxas.

Considerando otro orden de hechos, diversas concepciones del catolicismo dan soporte a teorías etiológicas de la enfermedad y a sus concomitantes prácticas terapéuticas. En este sentido, debemos mencionar la visión dual de la persona conformada por un cuerpo, un alma y la idea de espíritu ${ }^{10}$. Nociones que otorgan

\footnotetext{
${ }^{9}$ Características similares se advierten en las prácticas curanderiles en España e Italia hoy en día Gómez Briones, (1996:554-55), Gómez García, (1996: 210-223), González Alcantud, (1996: 597), Guggino, (1996: 147)

${ }^{10}$ El concepto de espíritu fue refigurado y es una de las entidades que integra la persona, diferente del alma, vale decir el sujeto tiene un alma, un cuerpo, un espíritu y un nombre. De acuerdo con la teología bajo-medieval católica, el espíritu y el alma eran entidades diferentes (van der Leeuw, 1964:
} 
significado a las manifestaciones, etiologías y procedimientos curativos de ciertos males. En particular de aquellos que implican desequilibrios entre las entidades que integran la persona, como la pérdida del alma por susto o el rapto del alma o del espíritu que comporta la agarradura ${ }^{11}$.

En el tratamiento del susto se debe llamar al espíritu y/o alma del enfermo. Con este fin, el curandero separa la piel de la frente y sopla en dicha dirección para luego pronunciar el nombre del doliente, posibilitando que el espíritu reingrese a su habitual locus corpóreo. Para ubicar y comunicarse con el espíritu, el terapeuta da vueltas en las inmediaciones de la vivienda, mientras repite el nombre completo del enfermo, le pregunta dónde está y lo invita a regresar. Con el mismo objeto, agita la mano mostrando al espíritu ropas u otras pertenencias del paciente, hecho que se fundamenta en una noción de corporalidad que involucra tanto la materia anímica como la vestimenta. La lógica de esta praxis radica en reunir las entidades, de cuyo equilibrio depende la salud. En ella el nombre juega un rol fundamental porque es la entidad que atrae al espíritu.

Un procedimiento semejante se utiliza en la atención de la agarradura, mal provocado por Pachamama, quien sustrae el alma de los individuos como castigo al incumplimiento o la mezquindad en las ofrendas rituales.

La agarradura suele ser ocasionada por el Diablo, quien causa el mal si las personas que han pactado con él no cumplen sus pedidos o violan el acuerdo. El accionar punitorio del Maligno debe entenderse, en este caso, en términos de contrapaso. Otras veces, enferma por pura malignidad sustrayendo el alma al individuo o compeliéndolo al suicidio (Balzano, 1985: 43).

Las posibilidades de que un incauto caiga en poder del Diablo aumentan en carnaval, lapso dominado por el demonio y en el que su presencia entre la gente no sólo es permanente, sino que además es convocada por los hombres a través de la ceremonia de desentierro. El Diablo gobierna desde el miércoles de ceniza hasta el

294 y ss.), tal como lo son hoy en día en muchas Iglesias Evangélicas. En lo que hace a las concepciones de la población del NOA, se entiende que al morir el individuo el alma -según el juicio que se haga de la vida de esa persona- se dirige al cielo, al purgatorio o al infierno, mientras que el espíritu queda en el plano terrestre merodeando y manteniéndose en contacto con los vivos, hasta que se hayan celebrado las misas necesarias y, en general, realizado las acciones rituales requeridas para que abandone este mundo y se reúna con el alma en el ámbito que le corresponda. Sobre las almas y el poder en el sujeto ver van der Leeuw, 1964.

${ }^{11}$ Pachamama castiga el incumplimiento o mezquindad ritual con la agarradura. El Diablo puede causarla por pura malignidad o por los pactos que realiza con los hombres. Sobre taxa de enfermedad en el NOA puede verse, además de los autores citados a Bianchetti, 1996. Sobre el Diablo ver Amaya, 1996; Forgione, 1996; Krause, 1995 y Torres, 2003/4. 
domingo de Pascua, lapso durante el cual algunos curanderos evitan ejercer la terapia por temor a ser tentados por el Maligno.

Para tratar la agarradura del Diablo, el doliente debe trasladarse hasta el lugar en que éste le sustrajo el alma, facilitando que el curandero descubra donde la escondió. Luego el sanador lucha con el propio Diablo para liberar el alma y adosarla al cuerpo del enfermo. En la cura de los males que implican desequilibrios religioso-rituales, se advierte con la mayor claridad el carácter sagrado de la terapia, expresado en la cantidad de poderes y seres que interactúan y se entrecruzan, tales como las deidades tradicionales -especialmente Pachamama- y del catolicismo Dios, Cristo, la Trinidad, el Diablo, vírgenes y santos-, el poder de los elementos y símbolos manipulados en los rituales terapéuticos, el poder del ambiente, de animales, vegetales y minerales, la calificación del espacio y del tiempo, el poder del sujeto a través del nombre, el cuerpo y el espíritu y, finalmente, el poder del terapeuta y el de sus espíritus auxiliares.

El nombre es una suerte de alma nombre, que -como vimos- juega un papel importante en la terapia y que, a la vez, puede ser objeto de daño. Contando con el nombre de una persona se puede proceder a su cura en múltiples circunstancias, en virtud de que desde la perspectiva de los actores sociales si bien el individuo no está físicamente, no está ausente sino presente a través de una de sus entidades, tan real y válida como la presencia corpórea. El nombre es a la vez especialmente manipulado en las acciones de daño, y pidiendo males específicos se escribe en velas, se entierra en cementerios, se lo congela en una heladera, se lo arroja al agua estancada, se ata o se desata a otros nombres para influir sobre la vida amorosa de las personas, entre otras posibilidades (ver Idoyaga Molina, 2002). Paralelamente, el tratamiento de la brujería connota la importancia del nombre. En efecto, suele llamarse al enfermo por su nombre para impedir la disociación de cuerpo y espíritu. En este caso, el llamado tiene un sentido preventivo y no terapéutico. La acción curativa que distingue a la brujería es la incineración real o simbólica del daño (Idoyaga Molina, 2002).

Señalemos, finalmente, que las emociones que se definen como pecados capitales -la envidia y la cólera- se asocian a manifestaciones de dos taxa ${ }^{12}$

\footnotetext{
12 Con la voz taxa -singular taxon- designamos a las denominaciones de las enfermedades tradicionales reconocidas por nombres específicos, tales como mal de ojo empacho, susto, culebrilla, etc. en cuanto categorías de un sistema clasificatorio.
} 
tradicionales: Ios nervios causados por sentimientos de ira o cólera y la envidia, que causa el mal homónimo. También la gula, la lujuria, la pereza, la avaricia y la soberbia aparecen en la etiología de males particulares, por ejemplo la gula como fundamento del empacho, aunque en especial se conectan a desequilibrios religiosorituales (Idoyaga Molina, 2003: 86).

Entre las acciones rituales son generales los rezos, la invocación a las deidades, el sahumado, el alumbrado con velas, el uso de agua bendita, las repeticiones de la señal de la cruz, la alusión a la Trinidad y a otros símbolos del catolicismo. El agua bendita, usada por su valor purificatorio y terapéutico, se da a beber y/o se rocía a los pacientes, tanto puede contribuir a sanar el empacho, disipar las energías negativas del malhecho, mitigar el dolor causado por el mal aire o contribuir a recuperar el alma del asustado, mientras que la aspersión se usa para limpiar ambientes corrompidos por la presencia de daños o de brujos. Suelen hacerse preparados a los que al agua se le agrega ruda, contra hierba y vinagre.

La señal de la cruz es un poderoso símbolo de sanación en cuanto connota la muerte y resurrección de Cristo. Es una acción absolutamente reiterada, el curandero suele santiguarse al empezar y al terminar el ritual terapéutico, la hace, además, sobre el cuerpo del doliente y con el sahumerio durante la cura. De acuerdo a los actores, el hacer la señal de la cruz posee una doble fundamentación: por un lado, invoca el poder y la protección de Dios y, por otro, implica un acto simbólico que actualiza el poder de Cristo, canalizado a través del curandero. Finalmente, la cruz -la habitual o la de Caravaca- suele colocarse en la entrada de las casas con fines preventivos.

Las invocaciones, las oraciones circunstanciales y los rezos estandarizados a las deidades ponen en escena otras de las técnicas terapéutico-rituales de origen católico. Se trata de acciones que realiza el curandero tanto en ocasión de la terapia junto al doliente como en los rituales que ejecuta solo, generalmente por la noche, para facilitar el diálogo con las entidades míticas.

Nos restaría ilustrar algunos tratamientos terapéuticos particulares originados en desequilibrios religioso-rituales. Las deidades y las figuras míticas del llamado catolicismo popular suelen castigar el incumplimiento ritual. Así por ejemplo, un individuo que tenía las imágenes de los Reyes Magos y habiendo llegado el 6 de 
enero no ofreció celebración ni ofrenda alguna ${ }^{13}$, padeció de derrame cerebral. Otros dolientes confiesan haber sido punidos por Dios Padre por inasistir al ritual de la misa y otros padecen algún mal por no cumplir con la promesa que le hicieran a un santo o a una virgen, a cambio de que les restituyeran la salud (Idoyaga Molina, 2002b: 134).

Las terapias en estos casos -en cuanto características particulares- exigen que el doliente rece y pida perdón a las deidades involucradas y, como acciones compensatorias, la realización de lo que fue omitido, vale decir una celebración a los reyes magos, la concurrencia a misa y el cumplimiento de la promesa al santo o virgen. Mientras que las técnicas implementadas por el curandero son de las que hemos denominado generales. El curandero procede a la invocación, rezos y alumbrado de velas, al sahumado de los pacientes con los vegetales habituales, a los que puede sumar fricciones en el cuerpo, ingestión de agua bendita y diversas infusiones vegetales, según los síntomas de cada paciente.

Recapitulando, como hemos visto, el concepto de enfermedad hace especial hincapié en el origen más que en los síntomas (Idoyaga Molina, 1999 y 2000a) y, entre otras causalidades, alude a aspectos mítico-religiosos, como castigo y/o venganza -por violación de un tabú, inobservancia ritual, etc.- y a acciones de daño de otras personas, como la brujería. Consecuentemente, las técnicas curativas apuntan a restaurar no sólo desequilibrios orgánicos, sino principalmente desequilibrios entre las entidades de la persona, desequilibrios sociales, desequilibrios ambientales y desequilibrios religioso-rituales a través del manejo de poder, de la sacralidad de los seres míticos y de los ritos establecidos.

Las figuras de santos, vírgenes, Cristo e incluso Dios Padre son fundamentales puesto que actúan como iniciadores y auxiliares del curandero, pueden causar enfermedades y constituyen arquetipos, cuyas acciones suelen actualizarse por repetición ritual. Por su parte, la figura del Diablo se asocia a la enfermedad y a otros daños, a la brujería y a los brujos, a la calificación del tiempo de carnaval y al ámbito nocturno. La significación de la mayoría de los elementos utilizados se funda en las creencias y símbolos del catolicismo, combinados con

\footnotetext{
${ }^{13}$ Los poseedores de imágenes de seres míticos deben ofrecer una fiesta en su honor en su día calendárico. El dueño de la imagen es generoso para ser socialmente respetado y seguir contando con la protección de la figura.
} 
otros elementos de la medicina principalmente humoral, refigurada por concepciones mítico-religiosas.

\section{Los ensalmos y sus significados mítico-religiosos}

Actualmente, la técnica terapéutico-ritual más extendida entre los legos es la cura de palabra o ensalmo que es útil para variadas dolencias. La mayoría de los adultos en los contextos rurales conocen fórmulas para diversas enfermedades, tales como las quemaduras, el empacho, los desgarros, la hernia, la angina, el dolor y ardor de estómago, el dolor de muelas, las verrugas, las hemorroides, el susto, el mal de ojo y el daño. Existen además "palabras" para curar animales, sembradíos y mejorar las condiciones climáticas o "cortar" las tormentas.

Estas fórmulas son secretas y sólo se transmiten en Viernes Santo, Nochebuena o en vísperas de San Juan. Normalmente, quien enseña dice la o las oraciones y el aprendiz las graba en su memoria. Ambos deben estar en ayunas, condición que también se recomienda en ocasión del uso terapéutico.

Este procedimiento fue calificado como mágico o místico no sólo por autores que trabajaron en la región que nos ocupa (Palma, 1978 y Pérez de Nucci, 1989), sino también en Argentina por investigadores que han enfocado la población criolla de las provincias del Litoral (García, 1984 y Jiménez de Puparelli, 1984 a) y del nordeste (Sturzenegger, 1999). Incluso historiadores del medioevo y la modernidad en España, que enfocan -por necesidad- el traslapo entre medicina y religión y que reconocen la existencia de terapéuticas religiosas, tales como las prácticas de niños consagrados, de santos, de sacerdotes, entre otras, calificaron a los ensalmos como acciones mágicas (Campagne, 1996: 200-2007).

Campagne, por ejemplo, refiriéndose a los rituales terapéuticos en la tradición española, los integra en las curas mágicas, las que entiende como opuestas o, al menos, diferentes a las religiosas (1996: 200-2001). En lo relativo al NOA, Palma (1978: 168) sostiene que es un tipo místico de terapia, a pesar de que se suele usar en el tratamiento de males de origen natural. Pérez de Nucci (1988: 111) a pesar de que reconoce la existencia de una terapéutica ritual de origen católico, clasifica a los ensalmos, siguiendo a Palma, como terapias místicas o mágicas. 
De acuerdo con Campagne la vía mágica comprometía a los ensalmadores que curaban a través de la palabra (1996: 216-220). Siguiendo al mismo autor: "Estos especialitas por lo general conjugan tres recursos: la gracia innata sobrenatural, el empleo de ritos y palabras y la aplicación de ciertos remedios naturales" (1996: 216). Campagne entiende que los ensalmos eran una variedad de los conjuros y como tales una de las formas básicas de acción del pensamiento mágico, que se distinguiría de la acción o pensamiento religioso evidenciado en la oración. La diferencia fundamental entre magia y religión radicaría en que las oraciones (religión) suplican favores a poderes divinos, mientras que los conjuros (magia) ordenan que se cumpla imperiosamente lo que se desea obtener. Siguiendo este razonamiento en la magia no se implora sino que se ordena la expulsión de la enfermedad debido al poder de las palabras empleadas (1996: 221-222).

Más allá de su clasificación, el autor reconoce que se usaban indistintamente los términos conjuro y oración porque "...los hombres de los siglos XVI y XVII no siempre lograban diferenciar claramente la magia de la religión" y cita por ejemplo los errores de Fray Martín Castañega y Pedro Ciruelo (1996: 222).

En el NOA, Palma (1978: 168) sostiene que los ensalmos son un tipo místico de terapia y los asocia con la idea de enfermedad/sustancia que penetra en el cuerpo como resultado del accionar de entidades malignas, cuyo arquetipo sería el mal aire. Las fórmulas actuarían en virtud de la fuerza de la palabra y agrega que este tipo de terapias es de trascendencia psicológica y puede ser de incuestionable importancia.

De acuerdo con el mismo autor, entre las terapias místicas existen ideas y praxis católico-religiosas que son compartidas por individuos de todos los sectores sociales (Palma, 1878: 42). No obstante, no establece subcategoría alguna que defina como religiosa, en el campo terapéutico que clasifica como místico.

Por su parte, Pérez de Nucci (1988: 62 y 1989: 69-70), clasifica los males en naturales y sobrenaturales, entre los últimos distingue: a) la impureza que es previsible o evitable mediante el tabú, b) la ingerencia extraña curable mediante la acción mágica y c) la explicación trascendente atendible a través de la religión (oraciones correspondientes al ritual católico) que suele combinarse con técnicas biomédicas o naturales. En lo relativo a los ensalmos, (Pérez de Nucci, 1988: 111) verificó su uso en el tratamiento de inflamaciones como el "dolor de muelas", cuya 
eficacia explica en términos psicológicos como transferencia y, siguiendo a Palma, identifica como terapias místicas, sin asociar los ensalmos a las acciones y creencias religiosas que reconoce como parte de la terapéutica tradicional.

En otras regiones también se ha registrado la cura de palabra. En Cuyo Krause (2006: 23) la incluye en el ámbito de lo sacro. En el Litoral -provincia de Entre Ríos- Jiménez de Puparelli (1984a: 243-245) ubica los ensalmos entre las acciones mágicas y agrega que, aunque las fórmulas son difíciles de conocer por su carácter secreto, ha constatado que aluden al Dios cristiano y a la Virgen y que en el ritual se debe mencionar el nombre de la enfermedad y del paciente. Asimismo, señala que, desde la perspectiva de los actores, son las deidades invocadas las que operan la sanidad. Así, la fórmula para el tratamiento del mal aire, por ejemplo, alude al Espíritu Santo y es seguida de tres oraciones del credo católico oficial (1984a: 245). La misma autora (Jiménez de Puparelli, 1984b:87) indica que la veterinaria tradicional incluye concepciones míticas, tal como se advierte en el empleo de la cura de palabra. En relación con el Litoral, pero esta vez en la Provincia de Corrientes, García (1984: 259) señala que en la medicina popular se advierten contenidos religiosos heredados de la tradición hispana, que se mezclan con saberes empíricos y prácticas mágicas. No obstante, al hablar de los ensalmos, los ubica entre las acciones mágicas. En el Nordeste, más precisamente en la Provincia de Formosa, Sturzenegger (1999: 66-67) explicando el sistema médico de los criollos habla de diferentes niveles de conocimientos entre los individuos de una comunidad rural. En el nivel más bajo, el del contexto familiar, la práctica de legos incluye el consumo de remedios caseros y de laboratorio, los que habitualmente se combinan con oraciones. Lo que es más, los actores suelen argumentar que la eficacia terapéutica también se debe a los rezos, la invocación de un santo o la mención del nombre de Dios. En un segundo nivel, se encuentran los poseedores de secretos, quienes -de acuerdo con la autora- saben fórmulas poderosas por sí mismas para curar algunas enfermedades y aclara que el tratamiento a través de las fórmulas suele acompañarse de infusiones, otros remedios e incluso otras técnicas rituales. En el último nivel se encuentra el especialista tradicional o curandero, capaz de atender cualquier dolencia. Es notorio que Sturzenegger no asocia las fórmulas con los ensalmos $y$, por ende, con la tradición terapéutica ritual de 
raigambre hispana que advierte en relación con los rezos e invocaciones en el caso de la medicina doméstica.

De acuerdo con lo expuesto, si bien los autores reconocen la integración de prácticas religiosas de raigambre católica en la terapéutica tradicional del NOA y de otras regiones del país, no incluyen aquí a la cura de palabra, técnica sobre la que, en rigor, aportan muy pocos datos y, a veces, pareciera que no la identifican con los ensalmos y la herencia hispana. En cierto modo, lo mismo puede decirse respecto de Campagne quien, refiriéndose a la medicina española de los siglos XVI y XVII, habla de técnicas propiamente religiosas y, sin embargo, incluye los ensalmos en el ámbito de la magia.

Otros autores han asumido posiciones diferentes, así por ejemplo Guggino señala que los actores sociales atribuyen valor mágico, por ejemplo, a un collar hecho con 7 dientes de ajo que se usa para combatir las lombrices, en cambio en relación con las fórmulas o conjuros repiten constantemente que "sólo tiene cosas de Dios" (1976:147). Una posición igualmente respetuosa del punto de vista de los usuarios toma Mariño Ferro, quien incluso habla de medicina religiosa (1996:42425). González Alcantud al hablar de los orígenes de la medicina occidental menciona la cura de palabra entre las terapias practicadas por los griegos (1996:592). Mientras que Spooner no duda del carácter religioso que poseen los versos terapéuticos que citan al Corán (1976:78), hecho que es de relevancia, ya que las tres religiones llamadas del "Libro", el Judaísmos, el Cristianismo y el Islamismo, han sido el marco cosmovisional o soporte ideológico de sistemas de creencias que incluyen ideas de enfermedad y técnicas terapéuticas, como lo han notado Moss y Cappannari en relación con el mal de ojo (1976: 5-8).

Volviendo a la etnografía de la cura de palabra en el Noroeste, en ocasión de la terapia, antes de pronunciar las fórmulas, el curador se persigna y suele hacer la señal de la cruz en la frente o en la parte afectada del cuerpo del doliente. En el tratamiento de algunas enfermedades, la enunciación de la fórmula es acompañada por otras técnicas, tal como sucede en la cura del empacho, de la culebrilla, la hernia, las hemorroides, las verrugas y el mal de ojo. Estas prácticas, aunque se reiteran, pueden variar según los conocimientos de cada curador ${ }^{14}$.

\footnotetext{
${ }^{14}$ Para curar el empacho se usa una cinta para realizar el diagnóstico y comprobar el éxito del tratamiento o se "tira el cuerito" mientras se recitan las fórmulas y se hace tres veces la señal de la cruz sobre la espalda del paciente antes y después de decir las oraciones. La culebrilla se cura 
Las palabras se dicen en silencio, invocando la ayuda y el poder de Dios, de la Virgen o de algún santo. El contenido refiere a la vida de Cristo, a la Virgen, al poder de la Santísima Trinidad y se decreta que la verdad enunciada se haga realidad en el enfermo, cuyo nombre se indica expresamente. A continuación se rezan tres Ave María o tres Padre Nuestro si en el texto se invoca a la Trinidad o alguna de las figuras que la integran, mientras que si el pedido compromete la intervención de un santo, una sola plegaria es suficiente.

La conexión entre el mal que aqueja al doliente y las palabras utilizadas varían. La relación es directa cuando la fórmula cita un episodio en el que Jesús curó esa misma enfermedad o cuando la oración hace referencia concreta a la dolencia padecida, señalándose que será curada en virtud del poder de la Deidad. Veamos algunos ejemplos:

Oración para las anginas y dolencias similares: "Nuestro Señor y San Martín iban por un camino, donde hallaron a San Pedro de bruces contra un canto rodado ¿Qué haces aquí? le dijo el Señor, y San Pedro contestó. "Me estoy muriendo del mal de anginas, de garganta y de flemones". A lo que el divino Maestro repuso: "Ponte los cinco dedos de la mano derecha y carrillos en honra y gloria a la Santísima Trinidad, y con el santo nombre de Dios el mal te será curado".

A través de la narración de un episodio del Nuevo Testamento en el que Cristo cura el mal que padece el enfermo, se actualiza su poder en el presente, el rezo se convierte en la acción de Cristo aquí y ahora. El episodio es fundante para la terapia de las anginas y además refiere la imposición de manos que es muy común en las terapias carismáticas y evangélicas y en el curanderismo actual en España.

Oración para las enfermedades en los ojos: "Nube, nube de sangre y agua formada, en honra y gloria de la Santísima Trinidad que sea prontamente curada".

En la fórmula se decreta que el mal será curado para lo cual se menciona cuál es la dolencia y se invoca el poder de la Trinidad, que opera la sanación de la dolencia.

Por otra parte, puede no haber conexión alguna entre la oración y la enfermedad que se va a atender, sólo se pide que tal o cual mal fuere curado después de decir la fórmula. Tal es el caso del tratamiento de la nostalgia:

escribiendo con tinta china y al revés Jesús, María y José en el extremo del herpe. La atención de hernias y hemorroides se acompaña del recorte del pie en una hoja de higuera o tuna. Las verrugas son contadas una y otra vez hasta su eliminación. 
“Jesús nació, Jesús murió, Jesús nació, Jesús murió, Jesús nació. Jesús murió. Así sea curada la nostalgia de N. N. Como estas palabras son ciertas".

La oración alude a un hecho cuya veracidad se reafirma y que es motivo de alegría para todo creyente, de ahí que actúe disipando la nostalgia, que como vemos no es parte de los hechos invocados y mencionados.

En muchas fórmulas se reitera la veracidad del hecho enunciado, lo que remarca su carácter fundante. Veamos una oración que ilustra lo dicho:

Fórmula para las quemaduras: "El fuego no tiene frío, el agua no tiene sed, el aire no tiene calor, el pan no tiene hambre. San Lorenzo, curad estas quemaduras por el poder de Dios constatado".

La mención de las distintas entidades indica el elemento que le es esencial, de este modo se define la realidad sin carencias y se opera, así, simbólicamente sobre toda carencia, en particular la dolencia mencionada, a través del poder de Dios que obviamente es un poder respetado por el creyente.

La invocación a los santos se funda en sus acciones, las que se relacionan en forma directa o indirecta con el mal que sufre el individuo. En algunos casos, el santo invocado atravesó los mismos pesares que el doliente, ha muerto en la hoguera como San Pantaleón o ha sido ciego, sordo, etc. En estos casos, lo emulado para que actúe simbólicamente es la carencia y no la abundancia, vale decir la lógica terapéutica que opera es la de la semejanza y no la de la oposición. Claro está que mediante la fórmula se hace presente aquí y ahora el poder del santo, quien en rigor es el actor de la cura.

Hay fórmulas que combinan ambas representaciones (oposición y semejanza), aludiendo por oposición a Dios Padre, Cristo o la Trinidad y por semejanza a un santo determinado.

Fórmula para la erisipela: "En nombre de Dios, Padre, Hijo y Espíritu Santo, de San Marcial, que ni por fuera ni por dentro te hagas ningún mal".

Como se advierte, se pide la salud -por oposición- a la Deidad que la posee y puede otorgarla, vale decir a la Santísima Trinidad, mientras que por semejanza se solicita piedad y sanación a San Marcial, quien sufrió de males diversos además de erisipela. Como en los otros casos, la fórmula actualiza el poder de las figuras invocadas, como el de la Trinidad. Se actualiza también el poder del santo que es 
arquetipo de sufrimiento y que, por ende, tienen el don para curar y transformar situaciones similares a los padecimientos que experimentara en vida.

En ciertas oportunidades, el santo es visto como un intermediario ante Dios y la semejanza entre la dolencia del enfermo y el padecimiento de la figura mítica es genérica, pues se alude a los múltiples sufrimientos que el santo soportó.

Constatamos también dinámicas de cambio como sucede con Santa Lucía, desde tiempos medievales requerida por los males de la vista (González de Fauve, 1996: 105) o para prevenirlos y, actualmente, también para curar el mal de ojo.

Algunas fórmulas introducen lo sagrado mencionando lugares significativos en la vida de Cristo. Veamos algunos ejemplos:

Fórmula para las anginas: "En Belén hay tres niñas; una cose, otra hila y otra cura las anginas, una hila, otra cose y otra cura el mal traidor".

Los personajes aludidos no poseen significación religiosa, la referencia a Belén es el hecho que liga la fórmula al poder de las deidades cristianas. Belén es el arquetipo mítico que da soporte a los tratamientos hechos hoy en día, en cuanto actualiza el poder de la deidad y de un espacio consagrado por el nacimiento de Jesús.

Fórmula para curar el cáncer: "El Cáncer y Jesucristo se van a Roma, el Cáncer se va y Jesucristo torna y viva Cristo y viva Cristo"

En este caso, los espacios mencionados y las idas y venidas, dejan simbólicamente el Cáncer en Roma y el retorno de Cristo es el hecho que fundamenta la sanidad, puesto que alude a las curaciones arquetípicas hechas por la Deidad, de las que dan cuenta los Testamentos.

Fórmula para limpiar los ambientes contaminados: "Que se vaya el mal y que entre el bien como hizo Jesús en Jerusalén".

La fórmula permite recalificar el espacio que se ha cargado de potencia negativa y, a la vez, proteger la casa y el ambiente que la circunda. La mención a Jesús y sus acciones opera como referencia mítica originaria y actualizable a través de la palabra. Así, como Jesús entró triunfante en Jerusalén, el ambiente corrompido por la brujería o la envidia será restaurado por el curador, imbuido del poder que le otorga la Deidad.

Como vemos, los ensalmos no necesariamente ordenan -como sostiene Campagne- más bien decretan nuevas realidades. 
Los ensalmos deben repetirse tres veces, preferiblemente en tres días consecutivos. Repetición que se apropia del poder sagrado del número tres, el que como dimos- deviene de ser el número de la Santísima Trinidad, relación que se hace evidente en la cantidad de oraciones que se rezan a continuación de recitar la fórmula según se mencione la Trinidad -o una de sus personificaciones- 0 simplemente otra figura, como la de un santo. La invocación y pedido a las deidades del catolicismo y la alusión a la Trinidad nos permiten afirmar que la cura es una muestra de su poder.

Tal como dijimos, la vida de Cristo fue mitificada, dando a los episodios del Nuevo Testamento la categoría de mito, más precisamente se trata de un ciclo mítico de carácter fundante respecto de diversos aspectos del dogma y del culto oficial, nos basta como ejemplo el ritual de la misa, que trae al presente su muerte y resurrección. Entre esos episodios fundantes narrados en los evangelios se destacan en el ámbito terapéutico la imposición de manos y la cura por ensalmos. Un proceso similar de mitificación se observa en relación con la vida de los santos canonizados por la Iglesia. En este último caso, el proceso de mitificación de la historia, o de los eventos históricos y particulares relacionados con una persona determinada, es dirigido avalado y actuado por la Iglesia al convalidar y certificar los milagros hechos por el humano que se está santificando o, en otras palabras, entrando en el mito. Lo mismo puede decirse de las múltiples apariciones de la Virgen que la Iglesia toma por verdaderas, generando cultos particulares y grupos de fieles, fenómeno muy extendido últimamente en América Latina y que Zambrano (2000 a y b) ha calificado como mitos remanecidos.

En este punto, vale la pena mencionar que los significados de los ensalmos citados por otros autores son básicamente similares a los ejemplos aportados por nosotros, en lo que hace a España a los dados por Campagne (1996), por Gómez García (1996: 212) y por Mariño Ferro (1996: 422-427) y en lo relativo a Italia por Appel (1976: 20) y De Martino (1959: 24). Tampoco son diferentes de las explicaciones y los materiales recabados por Krause (2006), García (1984) y Jiménez de Puparelli (1984 a) en lo relativo a la Argentina. Aunque en este último caso, cabe señalar que el resto de los autores, especialmente los que han trabajado en el NOA, parecen no haber recabado fórmulas ni tampoco registrado datos sobre 
los temas aludidos, sin necesidad de que el informante explicitara la fórmula literalmente.

Señalemos finalmente que son más fáciles de memorizar fórmulas cortas y que pueden no aludir explícitamente al poder de la Deidad. No obstante, la alusión es implícita y explicitable claramente como contenido de conciencia intersubjetivo entre la población criolla del noroeste argentino.

"Si viene gente y me pide que cure algo, los curo en nombre de Dios y de la Virgen, y digo las palabras para la enfermedad, siempre curo en nombre de Dios aunque sólo diga las palabras secretas para la enfermedad".

La misma noción aparece entre la población rural española en la actualidad, tal como se advierte en uno de los ensalmos transcriptos por Mariño Ferro (1996: 426):

Fórmula para expulsar el mal, la brujería o la posesión: "No es por mi poder ni por mi sabiduría, es por el poder de Dios y de la Virgen María. No soy yo la que corta (la enfermedad), que la corta la Virgen María con Jesucristo y la Santísima Trinidad".

En este sentido, el fundamento del ensalmo es absolutamente míticoreligioso. No hay formalmente diferencia alguna, en cuanto al mito hecho presente en el rito, entre la cura por ensalmos y la muerte y resurrección de Cristo en el ritual de la misa. Entendemos que no hay diferencias teóricas que impidan la utilización del concepto de mito como categoría explicativa. Asumir está posición implica estar más allá de las diferencias que pudiera establecer o re-establecer, introducir o reintroducir la liturgia y el dogma oficial de la Iglesia, históricamente cambiantes, especialmente en ocasión de los Concilios. Volviendo al tema del mito, en ambos casos se repiten hechos arquetípicos que se hacen presentes en el aquí y ahora que, por ejemplo, permiten al creyente nada menos que la comunión con Dios y a un individuo del NOA recuperar la salud. En nuestra posición de científicos sociales, al analizar un fenómeno socio-religioso en su contexto cultural de producción dejamos de lado las posiciones de la Iglesia y sus cambios (los que sí podrían hacer al interés de los estudiosos de las religiones en cuanto instituciones) y, por ende, nuestro análisis tiene soporte en la aplicabilidad de categorías teóricas como mito, historificación, mitificación, rito, sagrado, entre otras. Desde esta perspectiva, el hecho de que no compartamos la distinción entre magia y religión propuesta por los 
autores se vuelve secundaria ya que nuestra diferencia es más radical, podríamos decir de carácter teórico-metodológico, en cuanto calificar comportamientos, valores y creencias en virtud de la liturgia oficial de la Iglesia o partir de los sistemas de creencias y prácticas reales de los actores implican dos enfoques contrapuestos.

La cura por ensalmo requiere de la presencia del paciente cuando el rezo es acompañado de otras acciones -el caso del empacho y la culebrilla- mientras que no es necesaria en otras circunstancias, al terapeuta le basta con saber el nombre del doliente, el lugar donde se encuentra y el mal que la aqueja. Ello se debe a que como señalamos- el nombre es una de las entidades de la persona y, por ende, a través de éste se la puede sanar y dañar. En rigor, deberíamos decir que en ciertas ocasiones no es necesaria la presencia física del doliente en su encuentro con el terapeuta, que basta con la presencia del nombre, en tanto otra entidad del individuo.

La lógica de la cura por ensalmos responde a la idea de que palabras, pensamientos o intenciones son sustancias que fluyen de un emisor y que penetran en el cuerpo de la persona a la que van dirigidas. Estas palabras, pensamientos e intenciones actualizan el poder de las figuras míticas invocadas y tienen la capacidad enunciada en los rezos o definida en el pensamiento, de deshacer y/o expulsar la enfermedad/ sustancia del cuerpo del doliente. Esta cura manipula el poder de las deidades y los arquetipos y símbolos del catolicismo, que fundan su eficacia y legitiman su uso. Los actores son conscientes de que la sanación involucra el poder y la intención de la deidad. Sin embargo, no son siempre conscientes del origen de algunas de las prácticas rituales que ejecutan, por ejemplo, la relación entre la Trinidad, la sacralidad del número tres y el manejo del poder del número tres a través de la triple repetición de una acción. Este manejo puede aludir a la sacralidad del tres, sin embargo en las tres circunstancias el poder hecho presente es el de la Santísima Trinidad.

El empleo de ensalmos es de larga data, se usaban en España desde la Edad Media (González de Fauve, 1996: 106) y actualmente son utilizados por los curanderos (Gómez García, 1996: 212-216 y Mariño Ferro, 1996: 421-427). Se trata de un buen ejemplo para mostrar la influencia española en la terapéutica ritual de la medicina tradicional del NOA. 
En la praxis, el tratamiento de la mayoría de las dolencias que acompañan al ensalmo requiere del consumo de etnofármacos $y$, en algunos casos, de otras prácticas rituales. Mencionemos la eficacia curativa del rojo, cuyo simbolismo se asocia a la vida, a la fuerza, a la energía vital, como sucede con el tratamiento del sarampión y posee un perfil preventivo cuando se lo usa para evitar el mal de ojo, la envidia y la brujería (Idoyaga Molina, 1999: 20).

En síntesis, en el NOA el autotratamiento se vale de la combinación de los ensalmos -y los procedimientos asociados- con las ideas de la medicina occidental, principalmente la humoral, aunque refiguradas. El rito maneja el poder de símbolos y acciones del catolicismo y actualiza el poder del mito y de las acciones ejecutadas por las deidades que el mito narra, se vale también de los números sagrados y del simbolismo de los colores. La medicina humoral aporta las nociones de frío y cálido, las teorías de contagio por el aire y numerosas recetas, cuya eficacia pone en juego las representaciones sobre el poder de vegetales, minerales, animales y del ambiente.

Los ensalmos pueden usarse con fines negativos, inscribiéndose así en las teorías etiológicas del daño, brujería o mal hecho, también llamado "travesura", "mal puesto" o "mal postizo", en el NOA remiten básicamente a tres posibilidades: a) que la acción dañina la realice un brujo por encargo de otra persona, por contrapaso o por pura malignidad, b) que la acción dañina la realice un curandero por encargo de otra persona o para vengarse de quien le hubiera hecho alguna clase de maleficio $y$, c) que la acción dañina la realice un lego, en este caso pueden usarse fórmulas, aunque los meros sentimientos de envidia, celos y deseos negativos son suficientes ${ }^{15}$. En relación con el tema señala Bianchetti (1995: 9), que por medio de la palabra se puede enfermar a través de la mala boca (un taxon de enfermedad que refiere el hablar mal), los improperios y la maldición.

El uso dañino del ensalmo requiere que se pronuncie una fórmula determinada, indicando el nombre de la persona sobre la que se desea actuar, a

\footnotetext{
${ }^{15}$ Cabe aclarar que cuando hablamos de brujería como taxon de enfermedad respetando el punto de vista de los nativos, nos referimos al daño intencional provocado por otro ser humano $\mathrm{y}$, por ende, no incluimos el mal de ojo causado intencionalmente, pues para los actores se trata de otro mal. Del mismo modo, dejamos de lado los daños que puedan realizar las deidades o que resulten de la violación de tabúes, pues remiten a otras dolencias y nada tienen que ver con la voluntad de otras personas. Asimismo, es necesario aclarar que por brujo/a entendemos a los individuos que cuentan con poder y que lo canalizan en acciones de daño. La condición de brujo (witch) en términos de Murdock, puede adquirirse por pactos con el Diablo, o por la lectura de la Biblia negra, como dirían nuestros informantes.
} 
condición de que el individuo goce de buena salud. En este caso la víctima contraerá el mal que fuera involucrado y mencionado en la fórmula. Obviamente, en tales circunstancias no se actualizan los arquetipos y los seres míticos que facilitan la cura, vale decir la Trinidad, Cristo, la Virgen o los santos, sino que se instrumenta y manipula el poder del Diablo. Cabe acotar que en el sistema de creencias del catolicismo los rituales realizados en forma invertida, innecesarios o al revés operan un cambio radical, en tanto la potencia positiva se transforma en poder negativo y su sentido es invocar las entidades diabólicas. En este sentido, una misa iniciada por el final y concluida por el principio sirve para causar la muerte del individuo que es objeto del ritual, del mismo modo la ejecución de la señal de la cruz al revés denota el culto al Diablo.

Los ensalmos, al igual que la invocación a los personajes míticos y el manipuleo de otros símbolos del catolicismo, como la señal de la cruz, canalizan el poder de las deidades, concretándolo como capacidad terapéutica. Pero a la vez, pueden utilizarse con fines maléficos invocando a entidades demoníacas en virtud de que las creencias y vivencias del catolicismo definen dos dominios enfrentados: el divino o del bien y el demoníaco o del mal. El primero, se centra en la figura de Dios, a quien se asocia la salud y la terapia, mientras que el segundo, cuyo arquetipo es el Diablo, implica la brujería y la enfermedad y basta con invertir el uso de procedimientos rituales para transformar su significado. 


\section{Conclusiones}

Las medicinas tradicionales en el NOA son la medicina doméstica y el curanderismo. Ambas incluyen acciones rituales y creencias de raigambre católica, tales como invocaciones, rezos, alumbrados a las deidades, sahumados, comunicación con las deidades, el tratamiento no sólo del cuerpo del doliente sino también del alma, el nombre y el espíritu, teorías etiológicas de la enfermedad que incluyen la brujería y el daño intencional de otras personas, así como desequilibrios mítico-religioso-rituales, que incluyen a las deidades, los muertos y los espacios y tiempos calificados, el manejo de estados alterados de conciencia, la manipulación del poder sagrado de diversas entidades y de los símbolos del catolicismo.

El ensalmo es una de las más típicas terapias rituales de origen católico y aportada por la tradición hispana. A través de su puesta en acción se actualizan el poder sagrado y las acciones de las figuras míticas del catolicismo, tales como Dios Padre, Cristo, el Espíritu Santo, la Santísima Trinidad, una pléyade de manifestaciones de la Virgen María y numerosos santos y santas, principalmente oficiales, aunque últimamente hay palabras para San La Muerte. Las fórmulas son útiles para combatir la enfermedad de las personas y de los animales, los problemas de los sembradíos, limpiar los ambientes corrompidos, alejar las tormentas y prácticamente actuar sobre cualquier estado de aflicción que aqueje la existencia humana. Su eficacia se funda en que son acciones arquetípicas que, al repetir el modelo mítico, actualizan en el aquí y el ahora el poder de los seres mencionados y sus acciones, el ensalmo trae al presente el tiempo originario, ya fuere el mito emergente de la vida de Cristo narrado en los evangelios, ya fueren los mitos remanecidos que narran apariciones de la Virgen aquí y allá o el mito emergente a partir de las mitificación de la vida de los santos. Su uso ante la ausencia de la enfermedad o el infortunio que fuere, se transforma en mecanismo de daño y se pone en juego el poder de las entidades diabólicas. El ensalmo en cuanto actualiza, en el sentido de hacer presente, el poder de entidades míticas es metatemporal y su fundamento claramente explicable en términos mítico-religiosos, si tenemos en cuenta las experiencias, vivencias y contenidos de conciencia de los actores sociales que nos ocupan. Contenidos y vivencias que podrán, en más o en menos, 
tener que ver con la ortodoxia del catolicismo oficial. Ortodoxia que, por otra parte, no influye ni interesa al intentar la comprensión de las vivencias, de los contenidos de conciencia culturales o intersubjetivos de cualquier grupo social o cultural.

Desde la perspectiva expuesta, nos parece inadmisible la calificación de los ensalmos como curaciones mágicas frente a otras religiosas, aun sin compartir la idea de que la religión ora e implora y la magia ordena. Suposición que seguramente deja fuera del ámbito de lo religioso a numerosas manifestaciones de lo sagrado de las más diversas sociedades. En otras palabras, corre el riesgo de restringir los fenómenos religiosos: 1) a los sistemas de creencias de las religiones que Weber llamó institucionalizadas y, 2) dentro de estos fenómenos a los que las ortodoxias eclesiales definan como legítimos, dejando de lado las experiencias de los fieles y practicantes.

Digamos para concluir que sin conceptos como los de cuerpo, alma, espíritu, pecado, ensalmo, brujo, curandero, santos y vírgenes -que actúan como deidades iniciadoras-, Diablo, carnaval y, más en el general, el sistema de creencias del catolicismo asociado a tradiciones humorales y biomédicas, como los males y los remedios cálidos y fríos, el mal de ojo, el contagio de la enfermedad por los aires, la debilidad /fuerza de las personas y el riesgo de enfermedad, la importancia terapéutica de sabores, olores y colores, entre muchos otros ejemplos, las medicinas tradicionales del NOA carecerían de sentido.

\section{Bibliografía}

Álvarez Heydemreich, L. (1992) Tipos de curanderos en Hueyapan, Morelos. En: Roberto Campos (ed.) Antropología Médica en México, T. II. México: Universidad Autónoma Metropolitana.

Amaya, L. (1996) El Diablo Criollo. En: Cuartas Jornadas Nacionales de Folklore. Buenos Aires: Prensa del Ministerio de Educación.

Appel, W. (1976) The Myth of the Jettatura. En: Clarence Maloney (ed.) The Evil eye. New York: Columbia University Press.

Balzano, S. (1985) Ella no estaba sola. Análisis de un caso de suicidio en Rodeo Colorado. In: Scripta Ethnologica, IX. 
Bianchetti, M. C. (1995) Daño, ojeo y brujería en el Valle Calchaquí. En: Terceras Jornadas Nacionales de Folklore. 5-12. Buenos Aires: Prensa del Ministerio de Educación. 1995.

Bianchetti, M. C. (1996) Cosmovisión sobrenatural de la locura. Pautas populares de salud mental en la Puna Argentina. Salta: Ediciones Hanne.

Briones Gómez, R. 1996. Convertirse en curandero. Legitimidad e identidad social del curandero. Diputación Provincial de Granada: Granada. En: J. González Alcantud y S. Rodríguez Becerra (eds) Creer y Curar la Medicina Popular. Biblioteca de Etnología. Diputación Provincial de Granada: Granada.

Campagne, F. (1996) Cultura popular y saber médico en la España de los Austrias. En: Maria Estela González de Fauve (ed.) Medican y Sociedad: Curar y sanar en la España de los siglos XIII al XVI. Buenos Aires: Publicaciones del Instituto de Historia de España de la Facultad de Filosofía y Letras de la Universidad de Buenos Aires.

Cassirer, E. (1969) Antropología Filosófica. México: Fondo de Cultura Económica.

Coreil, J. (1995) Group interview methods in community health research. Medical Anthropology, 16 (3).

Csordas, T. y A. Kleinman (1996) The Therapeutic Process. En: Carolyn Sargent and Thomas Johnson Medical Anthropology. Contemporary Theory and Method. Westport and London: Praeger Publishers.

De Martino, E. (1959) Sud e Magia. Milán: Feltrinelli.

Eliade, M. (1968) El Mito del Eterno Retorno. Buenos Aires: EMECE.

Eliade, M. (1972) Tratado de Historia de las Religiones. México: Ediciones ERA.

Forgione, C. (1996) El tío, Diablo o Supay. Una realidad del mundo puneño. Scripta Ethnologica, XVIII.

Foster, G. (1976) Disease Etiologies in non-Western Medical Systems. American Anthropologist, 78.

Foster, G. (1994) Hipocrates' Latin American Legacy. Humoral medicine in the new world. New York: Gordon and Breach Science Publishers.

García, S. (1984) Conocimiento empírico, magia y religión en la medicina popular de los Departamentos de Esquina y Goya (Corrientes). En: Cultura Tradicional en el Área del Paraná Medio. Instituto Nacional de Antropología. Buenos Aires: Bracht Editores.

Gómez García, P. (1996) Teorías étnicas y etnológicas sobre la terapéutica popular. En: J.

González Alcantud, J. 1996. Creer y curar; Alea Médica, analogía estructural y apertura utópica. En: J. González Alcantud y S. Rodríguez Becerra (eds) Creer y Curar la Medicina Popular. Biblioteca de Etnología. Diputación Provincial de Granada: Granada. 
González Alcantud, y S. Rodríguez Becerra (eds) Creer y Curar la Medicina Popular. Biblioteca de Etnología. Diputación Provincial de Granada: Granada.

González de Fauve, M. S. (1996) Dos enfoques en el arte de curar: Medicina científica y creencias populares (España, siglos XIV al XVI). En: J. González Alcantud y S. Rodríguez Becerra (eds.) Creer y Curar la Medicina Popular. Biblioteca de Etnología. Diputación Provincial de Granada: Granada.

Guggino, E. (1996) Es el mago quien tiene que creer. En: J. González Alcantud y S. Rodríguez Becerra (eds) Creer y Curar la Medicina Popular. Biblioteca de Etnología. Diputación Provincial de Granada: Granada.

Gusdorf, G.(1960) Mito y Metafísica. Buenos Aires: Ediciones Nova.

Guss, D. (1981) Historical incorporation among the Makiritare: From legend to myth. In: Journal of Latin American Lore, 7 (1).

Hill, J. (1988) Myth and History. En: J. Hill (ed.) Rethinking History and Myth, Urbana y Chicago: University of Illinois Press.

Idoyaga Molina, A. (1999) El simbolismo de lo cálido y lo frío. Reflexiones sobre el daño, la prevención y la terapia entre criollos de San Juan (Argentina). Mitológicas, XIV.

Idoyaga Molina, A. (1999/2000) La medicina humoral, las nociones de cálido y frío y las prácticas terapéuticas tradicionales en la Argentina. En: Folklore Latinoamericano T. III. Buenos Aires: Confolk.

Idoyaga Molina, A. (2000a) La calidad de las prestaciones de salud y el punto de vista del usuario en un contexto de medicinas múltiples. Scripta Ethnologica, XXII.

Idoyaga Molina, A. (2000b) Natural and Mythical explanations. Reflections on the taxonomies of disease in North-Western Argentina (NWA). Acta Americana 8 (1).

Idoyaga Molina, A. (2001) Lo sagrado en las terapias de las medicinas tradicionales del NOA y Cuyo. Scripta Ethnologica, XXIII.

Idoyaga Molina, A. (2002a) Culturas, enfermedades y medicinas. Reflexiones sobre la atención de la salud en contextos interculturales de Argentina. Buenos Aires: Prensa del Instituto Universitario Nacional del Arte.

Idoyaga Molina, A. (2002b) The illness as ritual imbalance in Northwest Argentina. Latin American Indian Literatures Journal, 18 (2).

Idoyaga Molina, A. (2003) Los pecados capitales, las nociones de enfermedad y muerte en el Noroeste Argentino (NOA). Mitologicas, XVIII.

Idoyaga Molina, A. (2005a) Reflexiones sobre la clasificación de medicinas. Análisis de una propuesta conceptual. Scripta Ethnologica XXVII. 
Idoyaga Molina, A. (2005b) Una propuesta de categorías sobre las teorías etiológicas de la enfermedad de sociedades nativas y taxa vernáculos occidentales. VI Reunión de Antropología del Mercosur. Montevideo

Idoyaga Molina, A. (2006) El mal de ojo entre los Zapotecas (México) y las categorías conceptuales de Kearney: ¿Cosmovisión Paranoica u opresión étnica? Perspectivas Latinoamericanas, 3.

Idoyaga Molina, A y N. Luxardo (2005) Medicinas no convencionales en cáncer. Medicina, $5(2)$.

Jiménez de Puparelli, D. (1984a) Función de la Medicina Popular Entrerriana y su relación con la Medicina Oficial. En: Cultura Tradicional del Área del Paraná Medio. Instituto Nacional de Antropología. Buenos Aires: Bracht Editores.

(1984b) Aspectos tradicionales de la ganadería. En: Cultura Tradicional del Área del Paraná Medio. Instituto Nacional de Antropología. Buenos Aires: Bracht Editores.

Kleinman, A. (1980) Patients and healers in the context of culture. University of California Press: Berkeley.

Krause, C. (1995) El Diablo y los duendes cordilleranos. En: Selección de textos de Folklore del Mercosur. Buenos Aires: Prensa del INSPF- IUNA.

(2006) La envidia y su tratamiento. Reflexiones sobre el poder, la cura de palabra y otras terapias rituales en San Juan (Argentina). Mitológicas, XXI.

Moss, L. y S. Cappannari (1976) Mal'occhio, Ayin ha ra, Oculus Fascinus, Judenblick: The Evil Eye Hovers Above. En: Clarence Maloney (ed.). The Evil eye. New York: Columbia University Press.

Leenhardt, M. (1961) Do Kamo. Buenos Aires: EUDEBA.

Leeuw, G. van der.(1964) Fenomenología de la Religión. México: F. C. E.

Mariño Ferro, X.(1996) Los dos sistemas de la medicina tradicional. En: J. González Alcantud y S. Rodríguez Becerra (eds) Creer y Curar la Medicina Popular. Biblioteca de Etnología. Diputación Provincial de Granada: Granada.

Murdock, G. (1980) Theories of Illness: A World Survey. Pittsburgh: University of Pittsburgh Press.

Moll, A. (1944) Aescolapius in Latin America. Filadelfia: Sanders.

Otto, R. (1965) Lo Santo. Madrid: Revista de Occidente.

Palma, N.(1978) La medicina popular en el noroeste argentino. Buenos Aires: Ediciones Huemul.

Pérez de Nucci, A.(1988) La Medicina Tradicional del Noroeste Argentino: Historia y presente. Buenos Aires: Ediciones del Sol. 
(1989) Magia y Chamanismo en la Medicina Popular del Noroeste Argentino. San Miguel de Tucumán: Editorial Universitaria de Tucumán.

Redfield. R. (1934) Chan Kom: A Maya Village. Washington: Carnegie of Institute of Washington.

Sahlins, M. (1981) Historical metaphors and mythical realities. Ann Arbor: University of Michigan Press.

Spooner, B. (1976) The Evil Eye in the Middle East. En: C. Maloney (ed) The Evil eye New York: Columbia University Press.

Sturzenegger, O. (1999) Le mauvais oeil de la lune. Ethnomédicine créole en Amérique du Sud. Paris: KARTHALA.

Taussig, M. (1987) Shamanism, Colonialism and The Wild Man. Chicago and London: The University of Chicago Press.

Torres, S. (2003/4) Relatos sobre el Diablo en el Noroeste Argentino (NOA): La cuestión del pacto. En: Folklore Latinoamericano, Tomo VII. Buenos Aires: Confolk.

Turner, T. (1988a) Ethno-ethnohistory: myth and history in native South American representation of contact with western society. En: J. Hill (ed.) Rethinking History and Myth. Urbana y Chicago: University of Illinois Press.

(1988b)History, Myth, and Social Consciousness among the Kayapó of Central Brazil. En: J. Hill (ed.) Rethinking History and Myth. Urbana y Chicago: University of Illinois Press.

Young A. (1976) Internalizing and Externalizing Medical beliefs Systems. Un

Ethiopian Example. Social Sciences and Medicine, 10.

Zambrano, C. (2000a) Mito y etnicidad entre los Yanaconas del macizo colombiano. Mitologicas, Vol. XV.

Zambrano, C. (2000b) Mito e historia en la formación de comunidades plurales. Tres casos colombianos. Scripta Ethnologica, Vol. XXII. 